\title{
Experimentação e diversidade no processo de conhecimento em dança: o sistema artístico-pedagógico de Marilene Martins
}

Experimentation and diversity in knowledge processes in dance: Marilene Martins's artistic pedagogical system

Gabriela Córdova Christófaro ${ }^{1}$

1. Mariana de Lima e Muniz ${ }^{2}$

\section{RESUMO}

O conhecimento em dança é o tema deste artigo que aborda o sistema artístico-pedagógico criado por Marilene Martins, uma pioneira na dança de Belo Horizonte. O objetivo foi compreender a estrutura e a organização da proposta da artista-professora. Por meio de uma abordagem genética, conforme Salles (2008, 2009, 2014), fez-se um acompanhamento interpretativo de cadernos de artistas-professores. Foi possível perceber uma estrutura em rede caracterizada por mobilidade e inacabamento.

Palavras-chave: Dança. Processo de conhecimento.

Marilene Martins.

\section{ABSTRACT}

Knowledge processes in dance are the theme of this paper that approaches the artistic pedagogical system created by Marilene Martins, a dance pioneer in Belo Horizonte. The goal is to understand the structure and organization of the artist-teacher's proposal. By means of a genetic approach (SALLES, 2008, 2009, 2014), an interpretative analysis of notebooks created by artists-teachers was performed. It is possible to perceive a network structure characterized by mobility and unfinishedness.

Keywords: Dance. Knowledge process. Marilene Martins. e coreógrafa. Professora Assistente da Graduação em Dança da Escola de Belas Artes da UFMG. Doutoranda do Programa de Pós-Graduação em Artes da Escola de Belas Artes da UFMG. ORCID: 0000-0002-4088-1653.

2.

Atriz e diretora teatral. Professora Titular da Escola de Belas Artes da UFMG. Professora da Graduação em Teatro e do Programa de PósGraduação em Artes da UFMG. ORCID:0000-0003-3807-5.

Submetido em: 10/11/2017 Aceito em: 30/04/2018 
Introdução

Os processos de conhecimento em dança envolvem modos de fazer e sistemas metodológicos construídos por artistas, professores e pesquisadores, situados tanto no ensino formal como no ensino não formal. Este artigo aborda a proposta artístico-pedagógica de dança de Marilene Martins ${ }^{3}$, fundadora da Escola de Dança Moderna Marilene Martins, que posteriormente teve seu nome alterado para Trans-Forma Centro de Dança Contemporânea, e do Trans-Forma Grupo Experimental de Dança ${ }^{4}$. A artista é reconhecida por um trabalho pioneiro de dança em Belo Horizonte, que influenciou as gerações que se seguiram e os caminhos dessa arte na capital mineira (ALVARENGA, 2002; REIS, 2005).

A formação na área de Dança e temáticas correlatas têm sido relevantes no atual contexto brasileiro. Ressalta-se nesse panorama, nas duas últimas décadas, a criação de mais de quarenta cursos de graduação, nas modalidades bacharelado e licenciatura, em universidades públicas e privadas do país (SILVA, 2016; TERRA, 2010). Com isso, os percursos formativos nessa área passaram a abranger, além dos tradicionais cursos livres, normalmente situados em estúdios e academias, outros, como cursos técnicos, tecnológicos, de graduação e pós-graduação. Essas mudanças aconteceram juntamente com a ampliação do campo de trabalho do artista da dança ${ }^{5}$ que, conforme Rocha, configura-se como um território de invenção que envolve hoje várias e diferentes atividades, como "[...] ensinar, performar, criticar, coreografar, conversar, escrever, pesquisar, fazer curadoria, pensar, manter um site na web, lutar por publicações nos mais variados formatos, dirigir festivais, promover encontros etc." (ROCHA, 2010, p. 96).

Nesse estudo, o processo de conhecimento em dança proposto por Marilene Martins em sua escola foi desenvolvido com base na crítica genética, na perspectiva de Salles (2009). Trata-se do acompanhamento interpretativo de um dossiê formado por vinte e três cadernos de artistas-professores que atuaram junto à Martins. Esse material abrange registros relativos ao Curso Básico de Dança Moderna, criado por Marilene, que se constitui no objeto dessa pesquisa. Os cadernos foram produzidos no período de 1976 a 1984 e permitiram o acesso ao processo, que envolveu tanto a criação da proposta artístico-docente de Martins, como o trabalho desenvolvido pelos artistas-professores que a acompanharam. As anotações que constam nos cadernos compreendem exercícios e sequências de movimento, referenciais utilizados para realizar a movimentação e roteiros de aula. As questões que orientaram o acompanhamento interpretativo foram: quais os elementos que
3.

O trabalho de Marilene Martins (Brasil, 1935) na Escola de Dança Moderna Marilene Martins e no Trans-Forma Centro de Dança Contemporânea foi tratado por Arnaldo Leite de Alvarenga, em sua dissertação de mestrado, intitulada "Dança moderna e educação da sensibilidade: Belo Horizonte (19591975)" (ALVARENGA, 2002). Sobre a artista, consta também a publicação "Marilene Martins: a dança moderna em Belo Horizonte", de Christófaro (2010). Em 2012, Marilene Martins foi homenageada pelo Projeto Figuras da Dança, da São Paulo Companhia de Dança (SP/ $\mathrm{SP})$, que tem direção de Inês Bogéa.

4.

A historiadora Glória Reis aborda o trabalho de Marilene Martins e do Trans-Forma Grupo Experimental de Dança, no livro "Cidade e palco: experimentação, transformação e permanências" (REIS, 2005).

5.

A Classificação Brasileira de

Ocupações (CBO/2002), do

Ministério do Trabalho do Brasil, assim define a profissão de artista da dança: "Concebem e concretizam projeto cênico em dança, realizando montagens de obras coreográficas; executam apresentações públicas de dança e, para tanto, preparam o corpo, pesquisam movimentos, gestos, dança, e ensaiam coreografias. Podem ensinar dança" (Disponível em: <http://www.mtecbo.gov.br/ cbosite> Acesso em: 21 Set. 2017). 
estruturam a proposta artístico-pedagógica de Marilene Martins? Como esses elementos foram organizados?

\section{Marilene Martins: a opção por uma dança de vanguarda}

Marilene Martins apresenta uma trajetória de formação em dança de caráter diversificado do ponto de vista técnico e artístico. Ressalta-se também o contato da artista com pioneiros da dança cênica brasileira e sua participação em momentos cruciais para a construção dessa arte em Minas Gerais e no Brasil, na segunda metade do século $\mathrm{XX}$.

Marilene iniciou seus estudos em 1952, com Carlos Leite ${ }^{6}$, fundador da primeira escola de dança de Belo Horizonte, com vistas à profissionalização. O dançarino, que havia estudado na escola do Teatro Municipal do Rio de Janeiro 7 e integrado seu Corpo de Baile $^{8}$, dedicou-se ao balé clássico de origem russa, fortemente influenciado pelos Ballets Russes ${ }^{9}$ (CERBINO, 2008; PEREIRA, 2003; REIS, 2010). Dessa fase, Marilene ressaltou o que foi mais significativo para sua formação: "Ele me deu muita disciplina e perseverança, e uma boa base técnica" (Manuscrito de Marilene Martins. Acervo da artista, [197-]).

Após os estudos com Carlos Leite, a artista esteve junto a Klauss Vianna ${ }^{10}$ e sua esposa, Angel Vianna ${ }^{11}$, fundadores do Ballet Klauss Vianna ${ }^{12}$, que iniciaram o movimento moderno de dança na capital mineira. Nesse período, de 1956 a 1960, Marilene compartilhou das inquietações de Klauss Vianna, com quem também estudou balé clássico, mas sob uma nova perspectiva, em que o movimento se encontrava aliado à consciência corporal. Além disso, com Vianna, o ambiente de ensino-aprendizagem se caracterizou pela relação dialógica entre professor e aluno. Marilene comenta sobre a importância dessa experiência: "Klauss me influenciou na pesquisa do movimento e me orientou com segurança na parte pedagógica" (Manuscrito de Marilene Martins. Acervo da artista, [197-]). Martins foi afetada também pela pesquisa coreográfica de Vianna, fundamentada em temas regionais, buscados no diálogo com outras artes e em elementos indígenas, africanos e ibéricos. O objetivo de Vianna era a construção de uma dança brasileira, como Marilene comenta: "O Klauss tinha como ideal criar um ballet fundamentado nos gestos e na cultura brasileira, mais próximo do nosso povo, do nosso jeito de ser e viver. Eu e Angel compactuávamos com ele este mesmo ideal" (Manuscrito de Marilene Martins. Acervo da artista, [197-]). Nessa época, junto aos integrantes do Ballet Klauss Vianna, Marilene fez parte de um grupo - a Geração
6.

Carlos Leite (Brasil, 1914; Brasil, 1995). Dançarino, coreógrafo e professor de dança. Estudou na Escola do Teatro Municipal do Rio de Janeiro, fazendo parte também da companhia de balé dessa instituição. Desenvolveu um trabalho pioneiro de dança na cidade de Belo Horizonte, fundando uma escola de dança e o Ballet Minas Gerais, atual Companhia de Dança do Palácio das Artes, companhia oficial do estado de Minas Gerais (REIS, 2010).

7.

Em 11 de abril de 1927 foi instituída, oficialmente, a primeira escola de danças do Brasil, no Teatro Municipal do Rio de Janeiro, sob direção da russa, Maria Olenewa (PEREIRA, 2003).

8.

O Corpo de Baile do Teatro Municipal do Rio de Janeiro iniciou suas atividades profissionais em 1936, sob direção da bailarina russa, Maria Olenewa (PEREIRA, 2003).

9.

Os Ballets Russes, sob direção do empresário Serge Diaguilev, caracterizaram-se por espetáculos inovadores que divulgaram a arte moderna através de obras de artistas da vanguarda europeia (PEREIRA, 2003).

10.

Klauss Vianna (Brasil, 1928; Brasil, 1992). Coreógrafo e pesquisador do movimento, o artista brasileiro desenvolveu uma pesquisa corporal de referência para atores e dançarinos. Publicou o livro, "A Dança", em que aborda seu próprio trabalho. A obra do artista é discutida por autores, como Alvarenga (2009, 2010) e Miller (2007).

11.

Angel Vianna (Brasil, 1928).

Dançarina, coreógrafa e pesquisadora do movimento. A artista brasileira fundou, em 1983, no Rio de Janeiro, a Escola Angel Vianna, e em 2001, a Faculdade Angel Vianna (RAMOS, 2007).

12.

Ballet Klauss Vianna. Companhia de dança criada por Klauss e Angel Vianna, no ano de 1958, em Belo Horizonte (ALVARENGA, 2010). 
Complemento ${ }^{13}$-, que se reunia em torno de temas relativos às atividades intelectuais e artísticas no cenário moderno que se desenhava. É possível perceber na trajetória de Marilene Martins uma formação artística contextualizada socialmente.

Em 1961, Marilene Martins se transferiu para a cidade de Salvador para cursar a primeira Graduação em Dança do Brasil, na Universidade Federal da Bahia, que se destacava por reunir intelectuais e artistas de vanguarda. Nessa instituição, Marilene acompanhou, principalmente, o artista de origem alemã, Rolf Gelewski ${ }^{14}$, de quem se tornou assistente em cursos ministrados por ele. Com Gelewski, que foi aluno de Mary Wigmann ${ }^{15}$ e Marianne Vogelsang ${ }^{16}$, Marilene teve contato com a dança moderna e desenvolveu estudos voltados para a improvisação, a composição e a criação coreográfica. A experiência de Marilene com Gelewski foi fundamental na construção do trabalho artístico-pedagógico que a artista desenvolveu, posteriormente, na capital mineira, como ela explica:

[...] eu trouxe o trabalho estruturado de dança moderna, influenciada pelo meu prof. Rolf Gelewski, que era expressionista. Fiz uma pesquisa e organização próprias, baseando-me nos seus ensinamentos e incluindo no currículo várias disciplinas criadas por ele na UFBA, tais como composição, improvisação, estudo do espaço e da forma, anatomia, rítmica, coreografia em grupo, filosofia de dança, buscando assim construir uma base sólida para o ensino da dança moderna [...] (Manuscrito de Marilene Martins. Acervo da artista, [197-]).

Marilene Martins ampliou e deu continuidade a sua formação por meio de cursos em diversas linhas de balé clássico e dança moderna, e ainda, de jazz, dança primitiva, belly dance, além de outros, como expressão corporal, teatro, música e história da arte. Destaca-se em sua trajetória uma viagem feita para a Europa e os Estados Unidos, em 1974, em companhia de Angel e Klauss Vianna. Na oportunidade, Marilene fez aulas e entrou em contato com artistas e professores, como a alemã, Gerda Alexander ${ }^{17}$, criadora da Eutonia ${ }^{18}$, e os norte-americanos, Alvin Ailey ${ }^{19}$, Alvin Nikolais ${ }^{20}$ e Murray Louis ${ }^{21}$, além de fazer aulas no estúdio de Joseph Pilates ${ }^{22}$, com professores formados por ele. No percurso formativo de Martins é possível perceber a interação com perspectivas diversas e pioneiras de dança, como aquelas voltadas para a consciência corporal, práticas de criação artística, improvisação e composição. A experiência formativa de Marilene Martins explicita seu interesse pela vanguarda artística e tecnicamente diversificada no campo de dança.
13.

A Geração Complemento reunia intelectuais e artistas e influenciou o cenário artístico de Belo Horizonte na década de 1950 (MACHADO, 2001).

14.

Rolf Gelewski (Alemanha, 1930; Brasil, 1988). Dançarino, coreógrafo e professor de dança. Trabalhou na estruturação da primeira Graduação em Dança fundada no Brasil, em 1956, na UFBA. O artista publicou vários livros sobre seu trabalho (PASSOS, 2015). 15.

Mary Wigmann (Alemanha, 1886;

Alemanha, 1973). A dançarina e coreógrafa foi uma das representantes da dança expressionista alemã. Estudou com Émile Dalcroze e Rudolf Von Laban, de quem foi assistente (FARO, 1989).

16.

Marianne Vogelsang (Alemanha, 1912; Alemanha, 1973). A dançarina estudou com Rudolf Von Laban e se destacou como artista da dança expressiva (PASSOS, 2015).

17.

Gerda Alexander (Alemanha, 1908; Alemanha, 1994). A alemã criou a eutonia, um trabalho inserido no campo da educação somática (FORTIN, 2011).

18.

A eutonia, criada por Gerda Alexander, é um trabalho corporal reconhecido no campo da educação somática. Conforme Alexander (1983, p. X), "a eutonia se baseia na sensação tátil consciente, no desenvolvimento da sensibilidade superficial e profunda".

19.

Alvin Ailey (EUA, 1931; EUA, 1989). O

dançarino norte-americano estudou dança moderna com Graham, Horton, Holm e Weidman. Também estudou balé clássico e teatro. Fundou a Alvin Ailey American Dance Theater, em 1958. Seu trabalho como coreógrafo reúne a dança africana, o jazz, a dança moderna e o balé clássico (FARO, 1989).

20.

Alvin Nikolais (EUA, 1910; EUA, 1993). Iniciou-se na carreira artística como músico. Estudou dança com artistas, como Martha Graham, Doris Humphrey e Charles Weidman. Desenvolveu um trabalho em que a dança foi posta em diálogo com outras artes (FARO, 1989).

21.

Murray Louis (EUA, 1926; EUA, 2016).

Dançarino e coreógrafo norte-americano (FARO, 1989).

22.

Joseph Pilates (Alemanha, 1883; EUA, 1967). Criador do Método Pilates (LEGG, 2011). 
Ao fundar, em 1969, a Escola de Dança Moderna Marilene Martins que, em 1981, passou a se chamar Trans-Forma Centro de Dança Contemporânea, Marilene deu continuidade às iniciativas modernistas de Klauss Vianna e estabeleceu, efetivamente, a dança moderna na capital mineira (ALVARENGA, 2002; REIS, 2005). Nena, como também a artista é chamada, criou ainda o Trans-Forma Grupo Experimental de Dança, em 1971, que se destacou pelo caráter vanguardista. O período de existência da escola de Marilene Martins e do Grupo Trans-Forma coincidiu com o período de ditadura militar estabelecida no Brasil com o Golpe de 1964. O trabalho da artista, iniciado em 1969, instalou-se como um movimento de resistência, acompanhando o movimento de democratização do país, marcado pela anistia aos presos e exilados políticos e a promulgação da nova Constituição Federal, em 1988. Alvarenga (2002) compreende que o Trans-Forma foi um espaço que possibilitou aos artistas e à juventude da época, a expressão desejada.

A escola de Marilene Martins e o Trans-Forma Grupo Experimental de Dança colocaram em cena expoentes da dança brasileira, como as artistas, Dudude ${ }^{23}$ e Denise Stutz ${ }^{24}$, a bailarina Miriam Pederneiras ${ }^{25}$ e o coreógrafo Rodrigo Pederneiras ${ }^{26}$, fundadores do Grupo Corpo ${ }^{27}$, o artista e professor, Tarcísio Ramos Homem ${ }^{28}$, o artista, pesquisador e professor, Arnaldo Leite de Alvarenga ${ }^{29}$, dentre outros nomes. Para Alvarenga (2002), o trabalho de Marilene Martins se caracterizou pelo engajamento social e marcou a construção da área de dança e o ensino dessa arte em Belo Horizonte.

Na escrita de Marilene percebe-se o desejo da artista por uma dança que permita a expressão e a manifestação humanas: "[...] Queria uma dança para todas as idades, todos os corpos e condições, onde as pessoas pudessem 'se dizer' através do movimento. [...] Recuperar o simples, o natural, o orgânico [...]" (Manuscrito de Marilene Martins. Acervo da artista, [197-]). É possível relacionar as ideias de Martins à geração da Judson Dance Theater ${ }^{30}$, que surgiu nos Estados Unidos, na década de 1960. Para Banes (1993), esse foi um movimento que estabeleceu parâmetros democráticos para a dança, o que envolveu a condição corporal, o tipo de treinamento do dançarino, a inserção de não dançarinos na prática de dança, entre outras características que deslocaram essa arte de sua perspectiva espetacular. Assim como os artistas da Judson, Marilene se interessou por um contexto acolhedor à diversidade técnica, artística e corporal. Ressalta-se que a diversidade corporal mencionada por Martins correspondeu a diferentes biótipos, o que, naquele momento, significava romper com uma
23.

Dudude (Brasil, 1958). A artista desenvolve trabalhos como dançarina, coreógrafa, professora e improvisadora. Manteve o Estúdio Dudude Herrmann, de 1994 a 2008, e a Benvinda Cia. de Dança, de 1994 a 2008. Atualmente, em seu ateliê na cidade de Casa Branca (MG), realiza encontros, aulas e residências artísticas ministradas por ela e artistas convidados. Disponível em

< http://www.dudude.com.br/>. Acesso em 21 Set. 2017.

24.

Denise Stutz (Brasil, 1955). Dançarina e coreógrafa brasileira, foi uma das fundadoras do Grupo Corpo e integrou a Lia Rodrigues Cia. de Danças. Atualmente, desenvolve trabalho independente. Disponível em <https:// www.conexaodanca.com.br/blank-3>. Acesso em 18 Mai. 2018.

25 .

Miriam Pederneiras (Brasil, 1958).

Dançarina, uma das fundadoras do Grupo Corpo (REIS, 2005).

26.

Rodrigo Pederneiras (Brasil, 1955).

Coreógrafo, um dos fundadores do Grupo Corpo (REIS, 2005).

27.

Grupo Corpo (BH/MG/BR). Fundado em 1975, o Grupo Corpo reúne mais de 20 obras coreográficas em sua trajetória, apresentadas no Brasil e no exterior. Disponível em <http://www.grupocorpo. com.br/>. Acesso em 18 Mai. 2018.

28.

Tarcísio Ramos Homem (Brasil). Dançarino, professor e diretor de dança e de teatro. Professor do Teatro Universitário da Universidade Federal de Minas Gerais (UFMG). Disponível em <http://somos.ufmg.br/professor/ tarcisio-dos-santos-ramos $>$. Acesso em 18 Mai. 2018.

29.

Arnaldo Leite de Alvarenga (Brasil, 1958). Dançarino, coreógrafo e pesquisador. Professor do curso de Graduação em Teatro e um dos criadores do curso de Graduação em Dança, da Escola de Belas Artes (EBA), da UFMG (ALVARENGA, 2010).

30.

Judson Dance Theater. Movimento que marca a dança pós-moderna nos EUA. Reuniu um grupo de artistas, como os dançarinos Yvonne Rainer, Steve Paxton, Robert Morris, Lucinda Childs, Trisha Brown, David Gordon, Fred Herko, Judith Dunn, entre outros (BANES, 1993). 
perspectiva de dança que ditava padrões físicos e acabava por restringir a expressividade de alguns.

A escola de Marilene Martins se desenvolveu aos poucos e, no início, a artista atuava sozinha. Com o tempo, algumas alunas e poucos alunos orientados por ela começaram a dar aulas. Esse processo de formação artística que, no caso de alguns dançarinos, mais tarde foi ampliada para uma perspectiva artístico-pedagógica, passou a fazer parte da dinâmica e da estrutura da escola, cujo corpo docente se destacava por ser especializado na linguagem proposta por Martins. Esse grupo de professores esteve vinculado, principalmente, ao Curso Básico de Dança Moderna, um pilar na estrutura formativa da escola, concebido e sistematizado pela artista. Para esse curso, com duração de cinco anos, Marilene, com a colaboração dos artistas-professores que a acompanharam, organizou conteúdos e criou sequências de movimento e exercícios. Esse trabalho coletivo, orientado por Marilene em reuniões semanais, foi minuciosamente registrado pelos artistas-professores em cadernos.

\section{Corpo-documento: a dança no papel}

As anotações feitas pelos artistas-professores que acompanharam Martins possibilitaram o acesso à proposta artístico-pedagógica, relativa ao Curso Básico de Dança Moderna de sua escola. Os cadernos reunidos para essa pesquisa explicitaram o trabalho coletivo realizado, em que os registros foram feitos por meio de um mesmo conjunto de traços, abrangendo textos escritos, desenhos da figura humana e do movimento, números para indicar o modo como as músicas eram utilizadas, e símbolos para a descrição de exercícios rítmicos e para indicar referenciais de corpo. Ressalta-se nos registros a coordenação entre textos redigidos e desenhos do corpo humano, que esclarecem sobre o posicionamento e a movimentação, como demonstrado no exemplo a seguir. A descrição é a seguinte:

1 - dobrar perna direita no ar

2 - cabeça sai do chão fora "olhar joelho"

3,4 - alongar a perna que estava dobrada (baixinho) levando o tronco junto, o corpo fica apoiado no cóccix; braços ficam na altura do joelho, coluna redonda (Cadernos de artistas-professores. [entre 1982 e 1984]).

O desenho apresentado na Figura 1 acompanha o exercício descrito: 


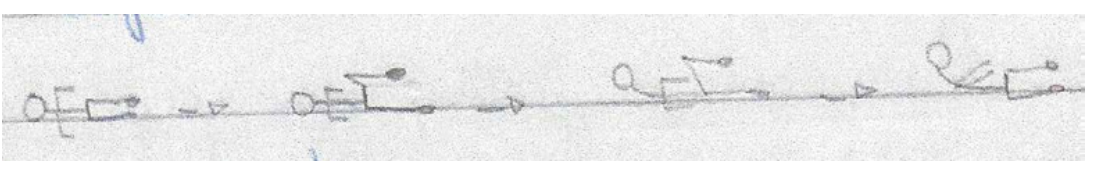

FIGURA 1. Texto escrito e desenho. Caderno de artista-professor, Belo Horizonte, [entre 1982 e 1984].

As notações de danças estão comumente relacionadas à análise e reconstrução coreográfica e do movimento, o que difere da abordagem desse estudo, em que seguimos na direção apontada por Louppe (1994), que ressalta a importância, não apenas histórica, mas também poética e intelectual desse tipo de material. Nesse sentido, o acompanhamento interpretativo dos cadernos dos artistas-professores foi o caminho escolhido para compreender o pensamento de dança de Marilene Martins.

\section{Rede de dança}

O interesse pela diversidade técnica e artística observada no percurso formativo de Marilene Martins é também evidenciado na proposta artístico-pedagógica do Curso Básico de Dança Moderna, concebido pela artista. A estrutura observada evidenciou um movimento em rede, a partir do que nos coloca Salles sobre processos de construção. Essa autora sugere que esses fenômenos sejam compreendidos conforme sua "natureza de rede complexa de interações em permanente mobilidade" (SALLES, 2009, p. 170). Também Musso (2013, p. 31), ao definir o conceito de rede como "[...] uma estrutura de interconexão instável, composta de elementos em interação, e cuja variabilidade obedece a alguma regra de funcionamento", aponta aspectos a serem observados em processos com essa configuração. São eles: os elementos existentes na estrutura, as interações entre eles e as condições que possibilitaram ou provocaram essas interações.

Ao observar a estrutura do Curso Básico de Dança Moderna, foram identificados alguns elementos fundamentais, chamados nesse estudo de materiais genéticos: um conjunto de sequências de movimento, criadas por Marilene Martins; trabalho de consciência corporal; rítmica; improvisação; e, diversidade técnica e artística em dança.

O conjunto de sequências de movimento criadas por Marilene Martins se constitui em um elemento perene na estrutura do Curso Básico de Dança Moderna. É possível perceber a possibilidade de ampliação desse conjunto por meio da criação de novas sequências. Mas, percebeu-se uma tendência à manutenção das sequên- 
cias criadas, de modo que se constatou o estabelecimento de um repertório de sequências de movimento. Marilene criou uma movimentação específica para cada um dos cinco anos do Curso, cujos conteúdos foram dispostos conforme finalidades determinadas (Manuscrito de Marilene Martins. Acervo da artista-professora. [197-]). No $1^{\circ}$ ano, destacou-se a sensibilização do corpo, o conhecimento da anatomia humana, especificamente os sistemas, esquelético e articular, e o desenvolvimento de conteúdos com base nos pés, postura, eixo e transferência de peso. No $2^{\circ}$ ano, foram enfatizados o sistema muscular e o trabalho de braços e pernas. No $3^{\circ}$ ano, o foco principal foi a soltura do corpo. No $4^{\circ}$ ano, a prioridade foram saltos e quedas. $\mathrm{E}$, no $5^{\circ}$ ano, destacaram-se os giros.

Esses conteúdos, apesar de serem enfatizados por níveis, eram todos abordados nos cinco anos do curso. Também as sequências, criadas especificamente para cada nível, podiam ser utilizadas em todos os outros níveis. Nesse sentido, percebeu-se que o processo de conhecimento não era proposto em uma perspectiva quantitativa, de acúmulo de conteúdos, mas sim, sob o ponto de vista qualitativo, de forma a propiciar a experimentação do movimento. A aprendizagem estava relacionada, sobretudo, à experiência do dançarino em um processo artístico, crítico e reflexivo, voltado para a experimentação e a compreensão de um mesmo movimento, sob vários ângulos. Apesar das sequências serem apresentadas de forma linear, seguindo a ordem dos níveis do curso, os roteiros de aula demonstraram uma proposição de aprendizagem não linear, em que as sequências podiam ser deslocadas de um nível para o outro.

Do ponto de vista formal, foi possível perceber que os movimentos característicos de técnicas de dança moderna fundamentaram o trabalho de Martins. Nesse contexto, há referências específicas à Técnica de Dança de Martha Graham ${ }^{31}$. Além desses, foram identificados, de modo pontual, movimentos do balé clássico. Com relação à dança moderna, foram identificados alguns aspectos, como a exploração da horizontalidade do corpo em trabalhos de chão, utilizando as posições deitada e sentada, como mostra a Figura 2:

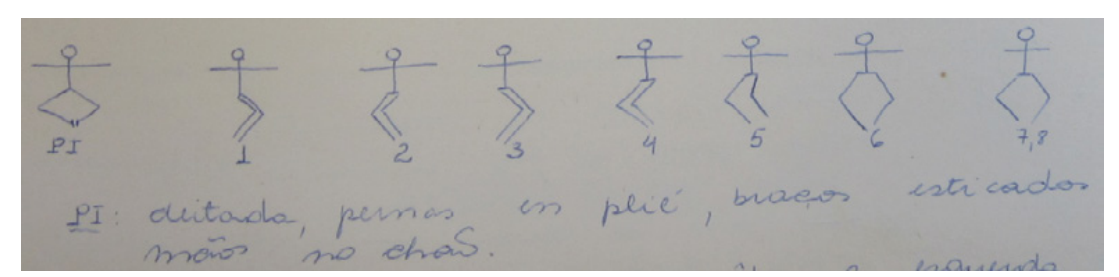

FIGURA 2. Movimento na posição deitada. Caderno de artista-professor, Belo Horizonte, [entre 1976 e 1984].
31.

Martha Graham (EUA, 1894; EUA, 1991). A artista criou novas expressões de movimento e é considerada uma figura fundamental na história da dança moderna norte-americana (LEGG, 2011). 
Outra característica das técnicas de dança moderna foi a utilização dos pés paralelos em sequências de chão, de barra e de centro, como mostra a Figura 3:

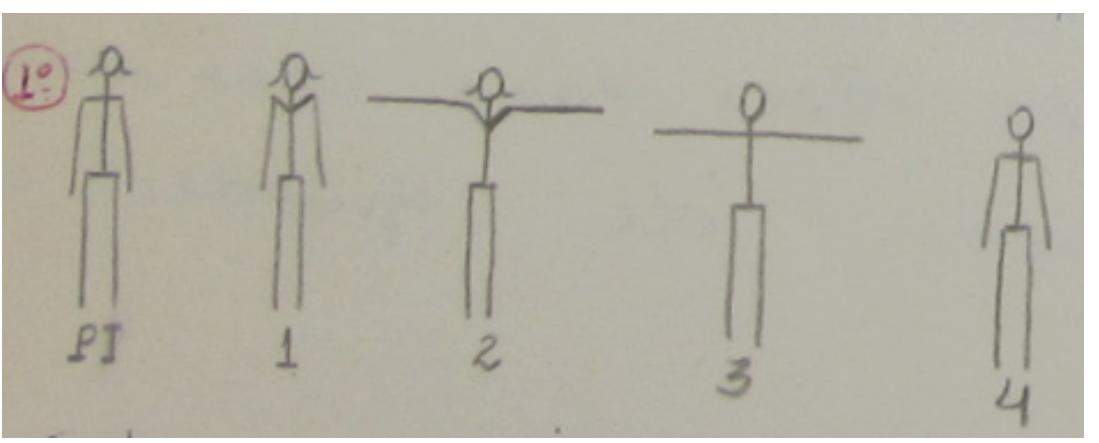

FIGURA 3. Pés paralelos. Caderno de artista-professor, Belo Horizonte, [entre 1976 e 1984].

Também foram encontrados outros aspectos, como os movimentos de tronco, em flexão, extensão, inclinação e torção, mostrados na Figura 4, e de braços, em movimentos ondulados, angulosos e assimétricos, como mostra a Figura 5.

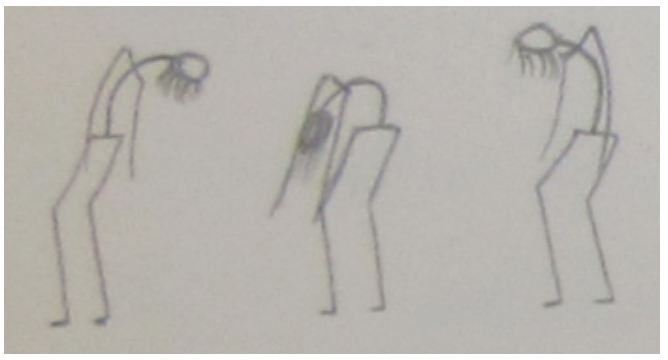

FIGURA 4. Movimento de tronco e cabeça. Caderno de artista-professor, Belo Horizonte, [entre 1976 e 1984].

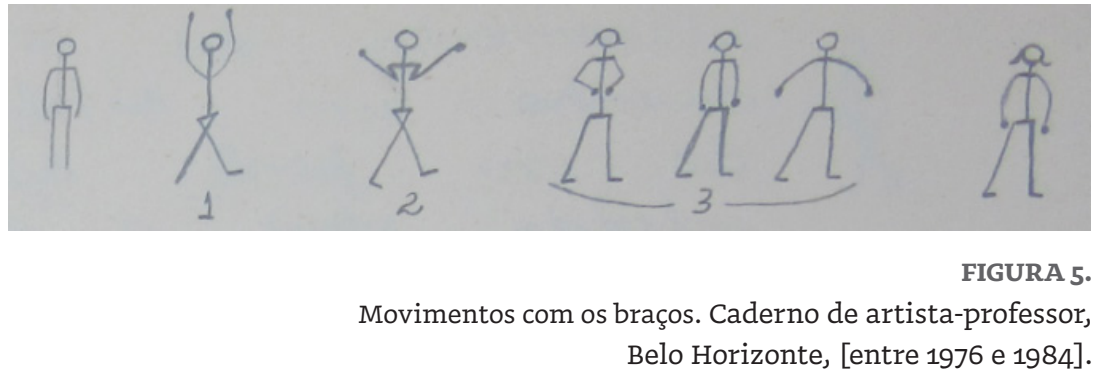

Foram encontradas, ainda, algumas características relativas aos modos de fazer o movimento, como a soltura do corpo a partir de parâmetros compartilhados pelo grupo de artistas-professores, a mobilidade articular, a combinação entre esforço e relaxamento e o caráter cotidiano na movimentação.

O trabalho de consciência corporal também se constituiu em material genético na estrutura do Curso Básico de Dança Moderna. A abordagem que Marilene fez do corpo se alinha ao campo da 
educação somática, de acordo com Hanna (1986). Na perspectiva desse autor a experiência corporal é um fenômeno de caráter proprioceptivo, voltado para a percepção do sujeito sobre si mesmo. No Trans-Forma, essas práticas foram utilizadas para abordar e estudar o corpo e também inseridas no estudo técnico de dança. Desse modo, a prática de dança no Trans-Forma propôs ao dançarino articular o movimento à percepção do corpo no movimento. Essa tem sido uma tendência de dança na atualidade que tem influenciado de forma importante o processo de aprendizagem, como discutido por Fortin (1998, 2005) e Domenici (2010), fato que fortalece a ideia do pioneirismo de Martins. Observou-se, principalmente, a aproximação entre a abordagem corporal de Marilene com as proposições de Klauss Vianna em que a perspectiva somática esteve apoiada na relação entre a dança e a anatomia humana (Manuscrito de Marilene Martins. Acervo da artista, [197-]). Cabe ressaltar uma diferença fundamental entre os trabalhos dos dois artistas. Se em Vianna, a prática de consciência corporal esteve aliada à técnica do balé clássico e ao seu trabalho de expressão corporal com atores e dançarinos, em Marilene, a percepção corporal possibilitou o trânsito entre diferentes técnicas de dança.

Conforme os registros dos roteiros de aula dos artistas-professores, a rítmica foi uma prática regular nas aulas e ocupou um espaço importante no Curso Básico de Dança Moderna. O trabalho com ritmos envolveu vários elementos, como: movimentação corporal, incluindo andadas, saltos, gestos e movimentos dançados; relação e uso do espaço, com exploração de deslocamentos em diferentes direções e percursos; utilização do elemento sonoro e percussivo, envolvendo o uso de sons vocais e palmas; exploração de palavras, canções e rimas, a partir de suas sonoridades e ritmos; uso do silêncio e de tempos e contratempos, dentre outras possibilidades.

Na estrutura do Curso Básico de Dança Moderna, a improvisação ocupou um espaço similar ao da rítmica nos roteiros de aula registrados pelos artistas-professores. Os exercícios de improvisação envolveram as relações entre o corpo, o espaço e o tempo, e também estímulos teatrais, ritmos e sons vocais. A ação de improvisar foi encontrada, ainda, com o sentido de experimentar as sequências de movimento ou o movimento em determinadas posições de corpo, como mostra a Figura 6.

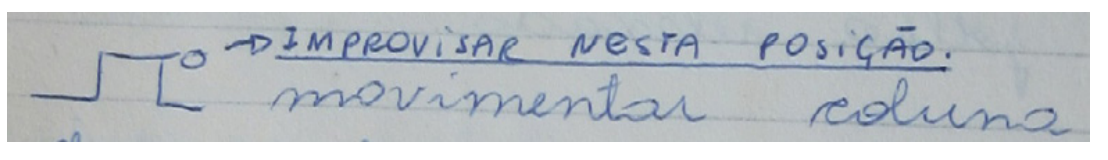

FIGURA 6. Improvisação - Caderno de artista-professor, Belo Horizonte, [entre 1976 e 1984]. 
Outro elemento fundamental nos registros do Curso Básico de Dança Moderna foi a diversidade técnica e artística em dança, como demonstrado na sequência de movimento da Figura 7.

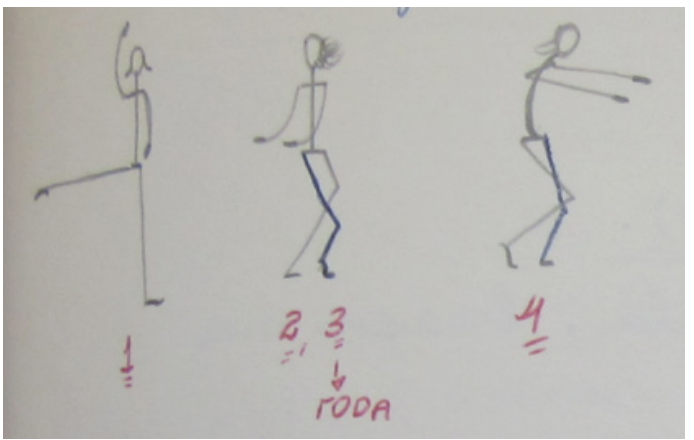

FIGURA 7. Diversidade técnica. Caderno de artista-professor, Belo Horizonte, [entre 1976 e 1984].

Essa composição com a utilização de diferentes referenciais pode ser constatada no enunciado do exercício. O primeiro movimento é descrito por meio de referenciais do balé clássico:

1 - Abrir a perna esquerda ao lado, subindo a perna direita em degagé em l'air à laseconde; simultaneamente subir o braço direito em $5^{\text {a }}$. posição e desenhar com a palma da mão voltada para a cabeça um círculo plano sobre a mesma, como uma auréola de anjo; o braço esquerdo fica na posição preparatória (Caderno de artista-professor, [entre 1976 e 1984]).

Nos trechos seguintes, para a descrição dos movimentos de tronco, a referência foi a dança moderna: "No $2^{\circ}$. tempo o tronco se curva para a direita, acompanhando o movimento dos braços; no $3^{\circ}$. tempo, rodar conservando esta posição; no $4^{\circ}$. tempo há uma pequena contração central" (Caderno de artista-professor, [entre 1976 e 1984]).

Observou-se que os diálogos estabelecidos por Martins não foram feitos aleatoriamente, o que pode ser exemplificado com a explicação da artista sobre a inserção de exercícios no roteiro de aula de uma turma de $3^{\circ}$ ano: "Enfatizam-se os trabalhos de soltura do corpo, integrando à dança moderna exercícios auxiliares de afro e belly dance, que se adaptam a esta finalidade" (Manuscrito de Marilene Martins. Acervo da artista, [197-]). Por meio das descrições, foi possível compreender que Marilene tinha objetivos claros quando fazia referência a exercícios e técnicas criadas por outros artistas e professores, integrando alguns deles a todo o percurso formativo do Curso Básico, ou inserindo-os em momentos específicos.

Processo de conhecimento em construção

A organização da estrutura do Curso Básico de Dança Moderna, verificada nos roteiros de aula dos artistas-professores, caracte- 
riza-se por mobilidade, demonstrada pelos vários intercâmbios entre seus elementos - conjunto de sequências de movimento; trabalho de consciência corporal; rítmica; improvisação; e diversidade técnica e artística em dança. Foram comuns as interações entre dois ou mais elementos para compor um exercício ou prática. Por exemplo, as sequências de movimento são, geralmente, descritas e explicadas a partir de referenciais corporais que integram o trabalho de consciência corporal. Também foi comum o uso de referenciais do trabalho de consciência corporal como estímulos para exercícios de improvisação. Desse modo, percebeu-se um ambiente de aprendizagem e fazer artístico em rede, suscetível às relações entre os elementos que compõem a rede, como discute Salles (2009).

Ressalta-se na estrutura do Curso Básico de Dança Moderna, principalmente, a experimentação de diversos referenciais técnicos e artísticos de dança. Por meio desses diálogos, observou-se a possibilidade de ampliação da estrutura do curso, o que configurou um movimento em rede. Desse modo, o processo de conhecimento em dança concebido por Marilene mantém seu estado em construção, ou seja, marcado por inacabamento (SALLES, 2009), e assim, permanentemente suscetível a diálogos e a constituição de novos pontos da rede. Nesse sentido, a diversidade se constituiu como uma condição favorável para o desenvolvimento da estrutura do Curso Básico de Dança Moderna. Assim, com uma trajetória marcada pela referência a vários artistas e professores, por meio do uso de seus exercícios, esse Curso foi sendo ampliado e transformado, a partir de uma estrutura inicial. Diante da dinâmica desse movimento, o processo de conhecimento em dança proposto por Martins se apresentou como um percurso continuamente recriado. Nessa perspectiva, o processo de conhecimento em dança e a construção desse processo de conhecimento em dança caminharam juntos. 


\section{REFERÊNCIAS}

ALEXANDER, Gerda. Eutonia: um caminho para a percepção corporal. São Paulo: Martins Fontes, 1983. 196 p.

ALVARENGA, Arnaldo Leite de. Klauss Vianna: abrindo caminhos. In: ALVARENGA, Arnaldo Leite de. Série Personalidades da Dança em Minas Gerais - Prêmio Funarte Klauss Vianna para Dança 2009. Belo Horizonte: Instituto Cidades Criativas, 2010, Livro 3. 95 p. ISBN: 978-85-61659-08-0.

ALVARENGA, Arnaldo Leite de. Klauss Vianna e o ensino de dança: uma experiência educativa em movimento (1948-1990). 2009. Tese (Doutorado em Educação) - Faculdade de Educação, Universidade Federal de Minas Gerais, Belo Horizonte, 2009.

ALVARENGA, Arnaldo Leite de. Dança moderna e educação da sensibilidade: Belo Horizonte (1959-1975). 2002. Dissertação (Mestrado em Educação) - Faculdade de Educação, Universidade Federal de Minas Gerais, Belo Horizonte, 2002.

BANES, Sally. Democracy's Body: Judson Dance Theater, 1962-1964. London: Duke University Press, 1993. 270 p. ISBN: 0-8223-1399-5.

CERBINO, Beatriz. Imagens do corpo e da dança: o Ballet da Juventude. IN: PEREIRA, Roberto; MEYER, Sandra; NORA, Sigrid (Orgs.). Seminários de Dança - Histórias em movimento: biografias e registros em Dança. Caxias do Sul, RS: Lorigraf, 2008. 250 p. ISBN: 978-85-99089-19-4.

CHRISTÓFARO, Gabriela Córdova. Marilene Martins: a dança moderna em Belo Horizonte. In: ALVARENGA, Arnaldo Leite de. Série Personalidades da Dança em Minas Gerais - Prêmio Funarte Klauss Vianna para Dança 2009. Belo Horizonte: Instituto Cidades Criativas, 2010, Livro 6. 95 p. ISBN: 978-85-61659-08-o.

Classificação Brasileira de Ocupações (CBO/2002), do Ministério do Trabalho do Brasil. Disponível em: <http://www.mtecbo.gov. br/cbosite>. Acesso em: 21 Set. 2017.

Conexão Dança. Disponível em <https://www.conexaodanca.com. br/blank-3>. Acesso em 18 Mai. 2018.

DOMENICI, Eloisa. O encontro entre dança e educação somática como uma interface de questionamento epistemológico sobre as teorias do corpo. Pro-Posições, Campinas, v. 21, n. 2 (62), maio/ ago. 2010. Disponível em: <http://www.scielo.br/pdf/pp/v21n2/ v21n2ao6.pdf >. Acesso em 18 Ago. 2016.

Dudude - Site oficial da bailarina e coreógrafa brasileira. Disponível em < http://www.dudude.com.br/>. Acesso em 21 Set. 2017.

FARO, Antonio José; SAMPAIO, Luiz Paulo. Dicionário de Balé e Dança. Rio de Janeiro: Jorge Zahar Editor Ltda, 1989. 426 p. ISBN: 85-7110-001-2. 
FIGURAS da Dança: Marilene Martins. Direção: Inês Bogéa. São Paulo: São Paulo Companhia de Dança, 2012, 1 DVD (28 min), widescreen, color.

FORTIN, Sylvie; LONG, Warwick. Percebendo diferenças no ensino e na aprendizagem de técnicas de dança contemporânea. Movimento, Porto Alegre, v. 11, n. 2, maio/agosto de 2005. Disponível em <www.seer.ufrgs.br/Movimento/article/download/ 2866/1480>. Acesso em 20 Nov. 2016.

FORTIN, Sylvie. Nem do lado direito, nem do lado do avesso: o artista e suas modalidades de experiência de si e do mundo. In: WOSNIAK, Cristiane; MARINHO, Nirvana (Org.). o avesso do avesso do corpo: educação somática como práxis. Joinville: Nova Letra, 2011. 256 p. ISBN: 978-85-7682-593-7.

FORTIN, Sylvie. Quando a ciência da dança e a educação somática entram na aula técnica de dança. Pro-Posições, Campinas, v.9, n.2 (26), junho 1998. Disponível em: <https://corpoemtransito.wordpress.com/2016/10/19/fortin-1998-quando-a-ciencia-da-danca-e-a-educacao-somatica-entram-na-aula-tecnica-de-danca/>. Acesso em 20 Nov. 2016.

Grupo Corpo. Site oficial da companhia de dança. Disponível em <http://www.grupocorpo.com.br/>. Acesso em 18 Mai. 2018.

LEGG, Joshua. Introduction to modern dance techniques. Hightstown: Princeton Book Company, Publishers, 2011. 252 p. ISBN: 978-0-87127-325-3.

LOUPPE, Laurence. Danses Tracées: Dessins et Notation dês Chorégraphes. Barcelone: Policrom, 2005. 158 p.

MACHADO, Lúcia Helena Monteiro. A filha da paciência: na época da Geração Complemento. Belo Horizonte: BDMG Cultural, 2001. 144p.

MARTINS, Marilene. Manuscrito trajetória artística de Marilene Martins. Acervo da artista. [197-]).

MARTINS, Marilene. Manuscrito Trans-Forma: técnica da escola. Acervo da artista. [197-]).

MILLER, Jussara. A escuta do corpo: sistematização da técnica Klauss Vianna. $3^{\mathrm{a}}$. Ed. São Paulo: Summus Editorial, 2007. 128 p. ISBN: 9788532303455 .

MUSSO, Pierre. A filosofia da rede. In: PARENTE, André (Org.). Tramas da rede: novas dimensões filosóficas, estéticas e políticas da comunicação. Porto Alegre: Sulina, 2013. 303 p. ISBN: 978-85-205-033-7.

PASSOS, Juliana Cunha. Rolf Gelewski e a improvisação na criação em dança: formas, espaço e tempo. Curitiba: Editora Prismas, 2015. 285 p. ISBN: 978-85-5507-085-3.

PEREIRA, Roberto. A formação do balé brasileiro: nacionalismo 
e estilização. Rio de Janeiro: Editora FGV, 2003. 332 p. ISBN: 85-225-0450-4.

RAMOS, Enamar. Angel Vianna: a pedagoga do corpo. São Paulo: Summus Editorial, 2007. 160 p. ISBN: 9788532303363.

REIS, Maria da Glória Ferreira. Carlos Leite: tradição e modernidade. In: ALVARENGA, Arnaldo Leite de. Série Personalidades da Dança em Minas Gerais - Prêmio Funarte Klauss Vianna para Dança 2009. Belo Horizonte: Instituto Cidades Criativas, 2010, Livro 2. 63 p. ISBN: 978-85-61659-08-0.

REIS, Maria da Glória Ferreira. Cidade e palco: experimentação, transformação e permanências. Belo Horizonte: Cuatiara, 2005. 166 p. ISBN: 85-85319-40-2.

ROCHA, Thereza. A dança depois da universidade: e agora? In: TOMAZZONI, A; WOSNIAK, C; MARINHO, N. (Org.). Algumas perguntas sobre dança e educação. Joinville/SC: Nova Letra, 2010. 228 p. ISBN: 978-85-7682-484-8.

SALLES, Cecília Almeida. Redes da criação: construção da obra de arte. $3^{\mathrm{a}}$. Ed. São Paulo: Editora Horizonte, 2014. 176 p. ISBN: 859929068.

SALLES, Cecília Almeida. Gesto inacabado: processo de criação artística. 4a . Ed. São Paulo: Annablume, 2009. 174 p. ISBN: 85-7419-042-X.

SALLES, Cecília Almeida. Crítica Genética: Fundamentos dos estudos genéticos sobre o processo de criação artística. $3^{\mathrm{a}}$. Ed. São Paulo: EDUC, 2008. 140 p. ISBN: 978-85-283-0372-8.

SILVA, Eliana Rodrigues. Graduação em Dança no Brasil: professor como orientador e aluno como protagonista. In: Instituto Festival de Dança de Joinville; Thereza Rocha. Graduações em dança no Brasil: o que será que será? Joinville: Nova Letra, 2016. 412 p. ISBN: 978-85-460-0127-9.

Somos UFMG. Disponível em <http://somos.ufmg.br/professor/ tarcisio-dos-santos-ramos>. Acesso em 18 Mai. 2018.

TERRA, Ana. Onde se produz o artista da dança? In: TOMAZZONI, A; WOSNIAK, C; MARINHO, N. (Org.). Algumas perguntas sobre dança e educação. Joinville/SC: Nova Letra, 2010. 228 p. ISBN: 978-85-7682-484-8. 